\title{
Modelling and forecasting of one-dimensional nonstationary heat transfer in building envelopes for energy efficiency building
}

\author{
Semjen Kundas, Elena Kresova \\ International Sakharov Environmental University, ISEU, Minsk, Belarus
}

Email address:

kundas@iseu.by(S. Kundas), elena-kresova@mail.ru(E. Kresova)

\section{To cite this article:}

Semjen Kundas, Elena Kresova. Modelling and Forecasting of One-dimensional Nonstationary Heat Transfer in Building Envelopes for Energy Efficiency Building. International Journal of Energy and Power Engineering. Vol. 2, No. 3, 2013, pp. 97-103.

doi: $10.11648 /$ j.ijepe. 20130203.12

\begin{abstract}
One-dimensional nonstationary heat transfer in three-layered building envelope is examined in this work. Therefore, initial and boundary conditions are examined. Possibility not only for modelling but for forecasting of heat transfer in capillary-porous structures of building envelopes is considered as well. For this purpose, time series analysis method was used. Standards for resistance of heat transfer in European countries and in Belarus are considered. Resistance to heat transfer of three-layer envelope where internal and exterior layers are precast layers and heat insulation is cellular polystyrene against heat insulation layer depth is examined as well.
\end{abstract}

Keywords: Heat Transfer, Envelope, Temperature Variation, Heat Insulation, Layer Depth

\section{Introduction}

Effectiveness increase of building envelopes heat insulation task is actual because of energy cost increase and problems with fuel and energy resources.

Energy efficient building of dwelling houses is one of the most important areas of development concept of building complex in Belarus pending 2011-2020 years. Energy efficient building volume is planned to lead up to 6 million $\mathrm{m}^{2}$, and it will compose about $60 \%$ of total area of new building. Rate of heat energy use on heating of these buildings don't have to exceed $60 \mathrm{~kW} \cdot \mathrm{h}$ on $1 \mathrm{~m}^{2}$ per year and in perspective to 2020 year don't have to exceed $30-40$ $\mathrm{kW} \cdot \mathrm{h}$ on $1 \mathrm{~m}^{2}$ per year. This is one of ways to optimize fuel and economy balance of country because Republic of Belarus consumes about $35 \%-40 \%$ of energy resources on heating and hot water supply of housing stock.

\section{National Energy Efficiency Program for 2011 - 2015 Years}

Long-term goal of activity in field of energy saving for a period to 2015 is energy intensity reduction of GDP of the Republic of Belarus on 50 percent to the level of 2005 year and increment of local supply-demand resources in balance of boiler-furnace fuel to 28 percent subject to ecological requirements, social standards and provision of energy safety indicators.

As a result of implementation of the national energy efficiency program for 2011 - 2015 years (1) specific heat consumption for heating and ventilation no more than $60 \mathrm{~kW} \cdot \mathrm{h}$ on $1 \mathrm{~m}^{2}$ per year after rebuilding and building reconstruction will be achieved; (2) building at least 60 percent of energy-efficient houses to 2015 year with specific heat consumption for heating and ventilation no more than $60 \mathrm{~kW} \cdot \mathrm{h}$ on $1 \mathrm{~m}^{2}$ per year for multistory buildings (from 4 to 9 floors) and no more than $90 \mathrm{~kW} \cdot \mathrm{h}$ on $1 \mathrm{~m}^{2}$ per year for low-rise buildings (from 1 to 3 floors) of volume construction will be achieved.

Energy efficiency will be provided on account of implementation of new energy-efficient technologies in all economic sectors and in technological processes. In building and production of building materials it will be achieved by (1) implementation of building materials with using of new energy-saving technologies; (2) design and building of houses with using of only energy-saving technologies; (3) realization of projects of apartment, public and office energy efficient buildings with forced and exhaust adjustable ventilation, with one coolant inlet in separate apartment (separate office) for organization of door-to-door heat metering and heat regulation of heat, with utilization of air 
emissions; (4) achievement to 2015 year building at least 60 percent of energy-efficient houses to 2015 year with specific heat consumption for heating and ventilation no more than $60 \mathrm{~kW} \cdot \mathrm{h}$ on $1 \mathrm{~m}^{2}$ per year for multistory buildings (from 4 to 9 floors) and no more than $90 \mathrm{~kW} \cdot \mathrm{h}$ on $1 \mathrm{~m}^{2}$ per year for low-rise buildings (from 1 to 3 floors) of volume construction; (5) design and implementation of devices for heat utilization of sewage in apartment and office buildings $[1,2]$.

\section{Mathematical and Physical Model of One-dimensional Nonstationary Heat Transfer}

\subsection{Different Models to Transport Heat}

Strict requirements are determined for energy consumption decrease in housing sector. First of all, it realizes thanks to heat-resistance envelope building coefficient increase. One of the most effective optimization methods of this important parameter is application computer modelling and forecasting of heat and humidity conditions of envelopes pending industrial process and operational process methods. It is impossible to solve this task with no account taken of environmental parameters. Particularly it is necessary to have information about air temperature and relative humidity variations in building constructions operational process. In this work possibility of modelling and forecasting of heat transfer using software COMSOL Multiphysics will be examined.

In building heat transfer, many different types of energy transport are effective. Often, heat is transported by different modes to or from the same place. Energy that reaches a point via different paths and modes may be added up for the heat balance [3].

Primary heat transport modes are: (1) conduction (heat flow on a molecular scale. Medium at rest or moving), (2) convection (heat conveyed as internal thermal energy of mass that is displaced by mean or turbulent motion) and (3) radiation (heat transfer by electromagnetic waves such as infrared or visible light). One can see these models in Fig. 1.

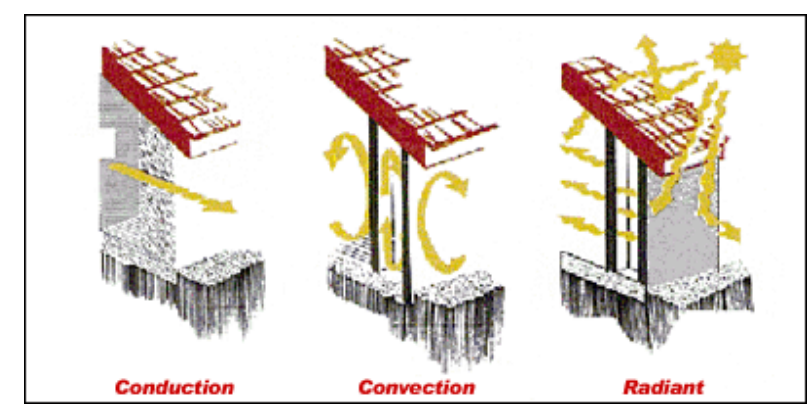

Figure 1. Primary heat transport models

In buildings, heat is also transported by the following mechanisms, which basically belong to the convective model: (1) transfer of latent heat by transport of water or water vapour, (2) thermal energy associated with the air replaced in a building by ventilation or by air leakage (infiltration), (3) thermal energy associated with fresh and used domestic water and combustion air (including flue gases), and fluids feeding heat pumps.

The transport of energy in the above list is limited to energy in the form of sensible or latent heat. A change of sensible heat is characterized by a variation of temperature while a change of latent heat is associated with some mass altering its phase. Phases are gaseous, liquid, solid. Transport of energy in forms other than heat are not considered.

Heat transfer in buildings may involve the listed types of transport. For an energy balance, other forms of energy often referred to as energy sources or heat loads - and dynamic (time-dependent) storage of heat in solid, liquid, or gaseous media have to be taken into account [4].

\subsection{Three-layered Exterior Walls Systems}

Three-layered exterior walls systems of stones, blocks and precast panels with heat insulation as centre are used for different buildings in new construction and reconstruction. They can correspond to bearing structure, non-bearing structure or self-bearing envelope.

Constructively systems are divided into next types:

(1) three-layered walls with cladding of stones and blocks and (2) walls of three-layered precast panels.

Examine walls of three-layered precast panels. System is erected of shop-mount panels. Three-layered precast panel is construction composed of internal and exterior precast layers and heat insulation located between them.

Internal and exterior precast layers are bearing structures. They receive all load and influences impacted on panel. They are made from armoured high-density and lightweight concrete.

Mineral cotton slabs, or staple glass fiber slabs, or cellular polystyrene slabs are used as heat insulation. They set between internal and exterior precast layers and heat insulation is concreted on end surfaces of panels. Heat insulation slabs have to have specified compressibility and moisture for support specified geometry [5].

\subsection{Initial and Boundary Conditions}

Thermal balance of heat entry from sources and loss them through surface of elementary volume for isotropic heterogeneous medium is expressed with classic differential thermal conductivity equation [6].

$$
\frac{\partial}{\partial t}(\rho c T)=\frac{\partial}{\partial x}\left(\lambda \frac{\partial}{\partial x}\right)+\frac{\partial}{\partial y}\left(\lambda \frac{\partial}{\partial y}\right)+\frac{\partial}{\partial z}\left(\lambda \frac{\partial}{\partial z}\right)
$$

where $\mathrm{p}$ - density of the material (medium); c - heat capacity for constant volume; $\mathrm{t}$ - time; $\mathrm{x}, \mathrm{y}, \mathrm{z}$-coordinates; $\mathrm{T}$ $=\mathrm{T}(\mathrm{x}, \mathrm{y}, \mathrm{z}, \mathrm{t})-$ temperature; $\lambda-$ thermal conductivity. 


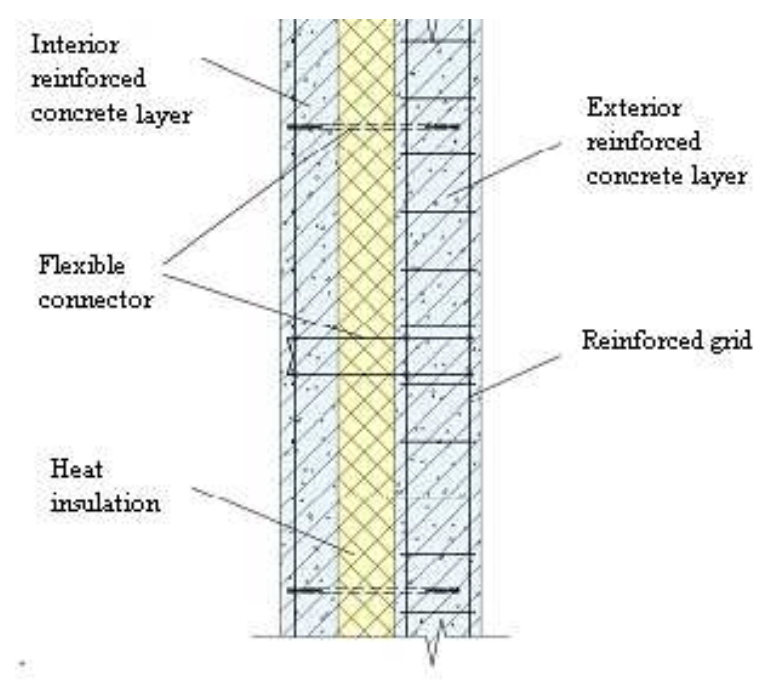

Figure 2. Precast panel.

Solving one-dimensional problem we take into account that temperature extends equally on envelope surface, i.e.

$$
\begin{aligned}
& \frac{\partial}{\partial x}\left(\lambda \frac{\partial}{\partial y}\right)=0 \\
& \frac{\partial}{\partial y}\left(\lambda \frac{\partial}{\partial z}\right)=0,
\end{aligned}
$$

and changes only in time $\mathrm{t}$ and in space (depth $\mathrm{x}$ of envelope). Thermal conductivity equation for one-dimensional task is

$$
\rho c(x) \frac{\partial T}{\partial t}=\frac{\partial}{\partial x}\left[\left(\lambda(x) \frac{\partial T}{\partial x}\right]\right.
$$

Thermal balance equation for every layer with additional conditions on boundaries of material layers can be written:

$$
\left\{\begin{array}{l}
c_{1} \rho_{1} \frac{\partial T_{1}}{\partial t}=\lambda_{1} \frac{\partial^{2} T_{1}}{\partial x^{2}} \text { for layer } 1 \\
c_{2} \rho_{2} \frac{\partial T_{2}}{\partial t}=\lambda_{2} \frac{\partial^{2} T_{2}}{\partial x^{2}} \text { for layer } 2 \\
c_{3} \rho_{3} \frac{\partial T_{2}}{\partial t}=\lambda_{3} \frac{\partial^{2} T_{3}}{\partial x^{2}} \text { for layer } 3
\end{array}\right.
$$

Where $\mathrm{T}_{1}$ is a center temperature of the first layer (interior precast layer), $\mathrm{T}_{2}$ is a center temperature of the second layer (heat insulation), $\mathrm{T}_{3}$ is a center temperature of the third layer (exterior precast layer).

On boundaries II (junction between first and second layers) and III (junction between second and third layers) boundary conditions of IV kind are defined. They determine equality of heat flux and temperatures:

$$
\begin{aligned}
& \lambda_{1} \frac{\partial T_{1}}{\partial x}\left|\mathrm{II}=\lambda_{2} \frac{\partial T_{2}}{\partial x}\right| \mathrm{II}, \quad T_{1}\left|\mathrm{II}=T_{2}\right| \mathrm{II} \\
& \lambda_{2} \frac{\partial T_{2}}{\partial x} \text { IIII }=\lambda_{3} \frac{\partial T_{3}}{\partial x} \text { |III, } \quad T_{2}\left|\mathrm{III}=T_{3}\right| \mathrm{III}
\end{aligned}
$$

On boundary I and IV complex heat exchange occurs. Heat exchange between interior envelope surface and indoor air and also between exterior envelope exchange and outside air occurs by convection. Then through materials layers heat exchange occurs by thermal conduction [6]. That's why on boundary I boundary conditions of II kind are defined (specified density of heat flux) written in (8). And on boundary IV boundary conditions of III kind are defined (specified conditions with environment) written in (9):

$$
\begin{aligned}
& \alpha_{\text {in }}\left(\mathrm{T}_{\text {in }}-\mathrm{T}_{i e}\right)=-\lambda_{1} \frac{\partial T_{1}}{\partial x} \mid \mathrm{I} \\
& \alpha_{\text {out }}\left(\mathrm{T}_{\text {out }}-\mathrm{T}_{\text {ee }}\right)=-\lambda_{3} \frac{\partial T_{3}}{\partial x} \mid \mathrm{I} V
\end{aligned}
$$

where $\alpha_{(\text {in,out })}$ - heat transfer coefficient of envelope surface with indoor (in) and outside (out) air which corresponds sum of coefficients of heat transfer by convection $\alpha_{c}$ and radiation $\alpha_{r}$, i.e. $\alpha=\alpha_{c}+\alpha_{r}$, $\mathrm{W} /\left(\mathrm{m}^{2} * \mathrm{~K}\right) ;\left(\mathrm{T}_{\mathrm{in}}-\mathrm{T}_{\mathrm{ie}}\right)$ - temperature difference between indoor air and interior surface of the first layer with thermal conductivity $\lambda_{1}$ and temperature $T_{1}$ in the center; $\left(T_{\text {out }}-\right.$ $\mathrm{T}_{\mathrm{ee}}$ ) - temperature difference between outside air and exterior surface of the third layer with thermal conductivity $\lambda_{3}$ and temperature $T_{3}$ in the center.

\section{Heat Insulation}

\subsection{Heat Insulation Market}

Heat-insulating materials are widely applicable in modern building. Building of different construction means their isolation and heat insulation. Heat insulation choice is one of the most important questions which have to be considered thoroughly. Every of heat insulation presented at market has its own running ability making it different among others. Belorussian heat insulation marker grows and develops complied their own rules.

Main part of responsibility for heat saving falls on building parts which contacts with environment taking part in heat exchange with it. There are walls, roof and floor. Heat leaves room and cold comes inside immediately through them. Using energy saving materials allows, as well as to minimize heat loss, reduce wall depth and building time, and cheapen cost of building.

There are a lot of different heat insulation materials. The most popular among them are cellular polystyrene, silicate cotton, fibre glass, foamed polyurethane, stone wool, expanded vermiculite, etc.

\subsection{Cellular Polystyrene}

Cellular polystyrene is produced by method of polystyrene foaming (styrene) and following sintering of foamed grains. In building this heat insulation is used 50 years. It is a light material well glued with other building materials. Advantages of cellular polystyrene are ecological compatibility, nontoxicity, low thermal conductivity $(0,030-0,040 \mathrm{~W} / \mathrm{m} \cdot \mathrm{K})$ and density $\left(15-40 \mathrm{~kg} / \mathrm{m}^{3}\right)$. Material is near nonageing.

Cellular polystyrene has high oxidation resistance and 
alkaline medium resistance. It has resistance to paints, alcohols, glues and bitumen as well. Cellular polystyrene strength allows use it as an element of construction surviving heavy loads during long time. Cellular polystyrene doesn't absorb moisture, doesn't be exposed to dote and doesn't create nutrient medium for bacteria and fungi. Useful time is unlimited.

Disadvantages of cellular polystyrene are vapor permeability in consequence of which outgoing from room moisture plugging happens and high work content. Owing to moisture plugging, microclimate changes in room. As a result wall efflorescence can be.

Cellular polystyrene is combustible material. That's why it is necessary to fulfill requirements of fire safety

As heat insulation cellular polystyrene is used in following constructions: (1) in plastering systems of external heat insulation, (2) in systems with heat insulation interiorly of building envelope, (3) in systems with heat insulation inside of building envelope (three-layered concrete or reinforced concrete panels, etc.), and so on.

\subsection{Resistance to Heat Transfer and Heat Insulation Layer Depth}

All countries have their own requirements for envelope heat-proofing features changing through time. You can see them in Table 1. Sometimes different values are provided for apartment and public buildings or for buildings with different shape. In addition minimum values for heat-proofing features are determined. They are presented in Table 2. In Italy, Denmark, Slovenia and Germany (for apartment buildings) heat transfer through building envelopes is limited with using average value of heat-proofing features; at the same time in Hungary heat transfer through building envelopes is limited with energy need for heating. In several countries (Italy, Spain, France) values of heat-proofing features vary against climatic conditions determined location including spacing from sea and height above sea level. Finland and Norway use less strict requirement for thermal protection of wood buildings for protection of wood building traditions [7].

Table 1. Desired value of resistance to heat transfer for standardized buildings in several European countries [7]

\begin{tabular}{|c|c|c|c|}
\hline Country & Year of a implementation & Type of building & Resistance to heat transfer, $\mathrm{m}^{2} \mathrm{~K} / \mathrm{W}$ \\
\hline France & 2005 & Apartment & 2,78 \\
\hline Belgium & 2008 & Apartment & 2,0 \\
\hline the Netherlands & 2011 & Apartment & 3,45 \\
\hline \multirow{2}{*}{ Germany } & \multirow{2}{*}{2009} & Apartment & 3,57 \\
\hline & & Public & $3,57 / 2,86^{*}$ \\
\hline Great Britain & 2010 & Public & 5,55 \\
\hline Italy & 2010 & - & 3.03 \\
\hline Hungary & 2006 & - & 2,22 \\
\hline Romania & 2006 & - & 1,41 \\
\hline Denmark & 2006 & - & 5,00 \\
\hline Norway & 2007 & - & 5,56 \\
\hline Sweden & 2008 & - & 5,56 \\
\hline Finland & 2010 & - & 5,58 \\
\hline
\end{tabular}

* For inside air temperature respectively $>19{ }^{\circ} \mathrm{C} /<19{ }^{\circ} \mathrm{C}$

** Threshold value or the hottest climatic zones of Italy

Table 2. Minimum values of resistance to heat transfer in several European countries [7]

\begin{tabular}{|c|c|c|c|}
\hline Country & Year of a implementation & Type of building & Resistance to heat transfer, $\mathrm{m}^{2} \mathrm{~K} / \mathrm{W}$ \\
\hline France & 2005 & - & 2,22 \\
\hline \multirow{2}{*}{ Germany } & \multirow{2}{*}{2009} & Apartment & $2,50-1,54$ \\
\hline & & Public & $2,86 / 2,001 *$ \\
\hline Slovenia & $2008 / 2010$ & $-\mathrm{c}$ & 3,57 \\
\hline
\end{tabular}




\begin{tabular}{llcc} 
Hungary & 2006 & - & 2,22 \\
Romania & 2006 & - & 1,41 \\
Denmark & 2006 & - & 2,5 \\
Norway & 2007 & - & 4,55 \\
Finland & 2010 & - & 1,66 \\
\hline
\end{tabular}

*. For inside air temperature respectively $>19^{\circ} \mathrm{C} /<19^{\circ} \mathrm{C}$

In pursuance of orders of president and government of the Republic of Belarus about energy protection, implementation energy efficient method of design, building and building reconstruction and using domestic energy saving and resources saving element of constructions, materials and energy saving engineering systems and also for complex solving of problem of increase building energy efficiency Ministry of architecture and building changed normative values of resistance to heat transfer of envelopes. New standard of resistance to heat transfer for building envelopes is $3,2 \mathrm{~m}^{2 \circ} \mathrm{K} / \mathrm{W}$.

In Table 3 you can see how resistance to heat transfer of three-layer envelope where internal and exterior layers are precast layers and heat insulation is cellular polystyrene changes against heat insulation layer depth.

Resistance to heat transfer is calculated by (10) [5]:

$$
R=\frac{1}{\alpha_{\text {in }}}+R_{c}+\frac{1}{\alpha_{\text {out }}}
$$

where $\alpha_{\text {in }}-$ coefficient of heat transfer of envelope interior, $\mathrm{W} /\left(\mathrm{m}^{2} \cdot{ }^{\circ} \mathrm{K}\right)$;

$R_{\mathrm{c}}$ - heat resistance of envelope, $\mathrm{m}^{2} \cdot{ }^{\circ} \mathrm{K} / \mathrm{W}$;

$\alpha_{\mathrm{H}}-$ coefficient of heat transfer of envelope outside for winter conditions, $\left.\mathrm{W} /\left(\mathrm{m}^{2} \cdot{ }^{\circ} \mathrm{K}\right)\right)[5]$.

Table 3. Resistance to heat transfer and heat insulation layer depth

\begin{tabular}{lc}
\hline Heat Insulation layer depth, $\mathbf{m m}$ Resistance to heat transfer, $\mathbf{~ m}^{2} \mathbf{K} / \mathbf{W}$ \\
\hline 120 & 2,5 \\
140 & 2,9 \\
160 & 3,3 \\
180 & 3,7 \\
200 & 4,1 \\
\hline
\end{tabular}

In Fig. 3 is shown graph of resistance to heat transfer of three-layered envelope building against heat insulation layer depth. Also on this graph old and new standards of resistance to heat transfer are presented which equal 2,5 и $3,2 \mathrm{~m}^{2 \circ} \mathrm{K} / \mathrm{W}$ respectively.

On presented graph you can see if heat insulation layer increases than resistance to heat transfer of building envelope increases, too. At the same time it is necessary to take into account that price of construction increases as well. If to consider that to 2020 year specific fuel consumption will go down to $30-40 \mathrm{~kW} \cdot \mathrm{h}$ on $1 \mathrm{~m}^{2}$ per year therefore it will determine new standards for resistance to heat transfer for building envelopes. That's why it will be necessary to apply new constructive, technological engineering decisions and engineering devices to reduce price of construction, to increase resistance to heat transfer and reduce depth of envelope.

Resistance to Heat Transfer for Building Envelopes Against Heat Insulation Layer Depth

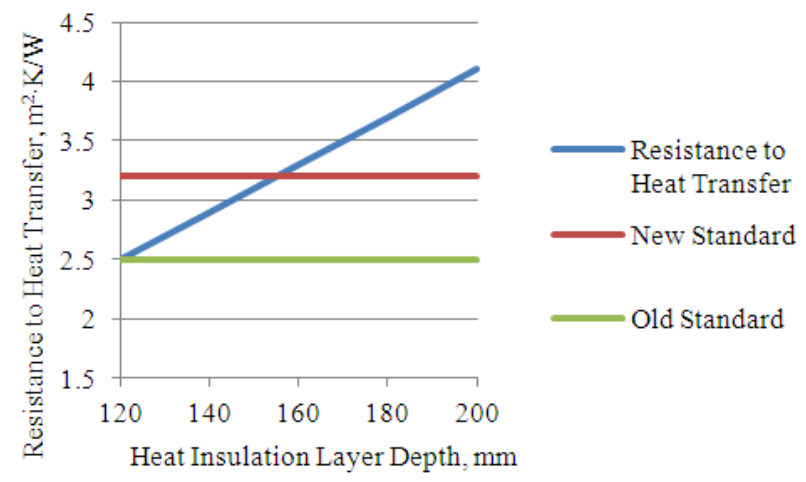

Figure 3. Resistance to heat transfer

\section{Result and Discussion}

Simulate heat transfer in three-layered envelope using software COMSOL Multiphysics where interior and exterior layers are precast panels and heat insulation is cellular polystyrene. Data are shown in Table 4 . On boundary I constant temperature was defined as $18^{\circ} \mathrm{C}$ and on boundary IV outside temperature was defined as air temperature variation in Minsk for two years.

In Fig. 4 temperature variation on boundary I (blue curve), in the middle of the second layer (green curve) and on boundary IV (red curve) are displayed. And in Fig. 5 temperature variation in profile of multilayer envelope is shown [8].

Air temperature variation is one of the most important parameters. For modelling and forecasting of heat transfer in envelope buildings we need know it. That's why time series model describing air temperature variation was built. For building a model time series parametric methods are used Temperature data were taken every 3 hours. Data for 20 years (from 1991 to 2010) are given by Belarusian State Institution «National Meteorology Centre». Data for the first 18 years were used for model building and the remaining two years were used for comparison with predicted values. 


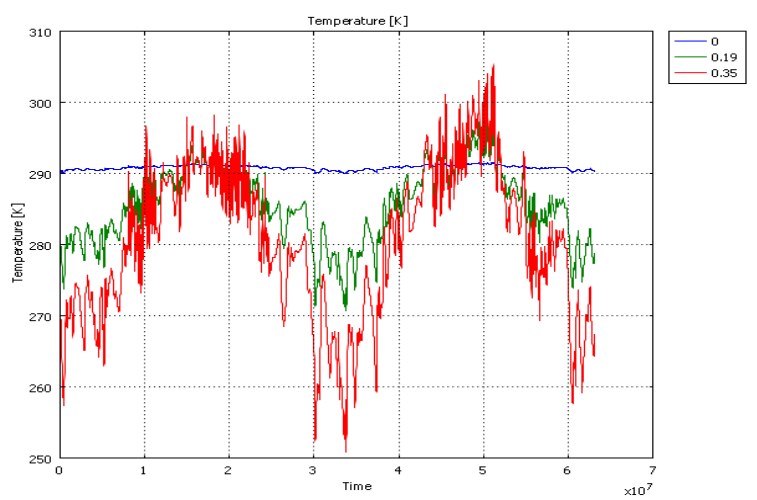

Figure 4. Temperature variation on different depth simulating of real data.

For model verification of predicted values coefficient of determination and standard deviation were used [9]. Coefficient of determination ranges from 0 to 1 . The closer coefficient of determination is to 1 the better model describes initial data. It was determined that coefficient of determination equals 0,79 , so one can say that target model rather well describes original time series because time series has a lot of observations. Standard deviation is $4,92^{\circ} \mathrm{C}$ [10].

Then we put predicted values in return for real data. From Fig. 6 is it possible to see how temperature changes on boundary I (blue curve), in the middle of the second layer (green curve) and on boundary IV (red curve). compared with temperature variation values of three-layered envelope simulating of real data. Verification showed that model of temperature variation of three-layered envelope simulating of additive time series model describes of high coefficient of determination.

Thereafter obtained temperature variation data of three-layered envelope simulating of predicted data were.

\section{Conclusions}

Nonstationary one-dimensional heat transfer in three-layered envelope buildings with interior and exterior layers from precast panels and heat insulation from cellular polystyrene was examined in this work. Initial and boundary conditions for this way were examined as well.

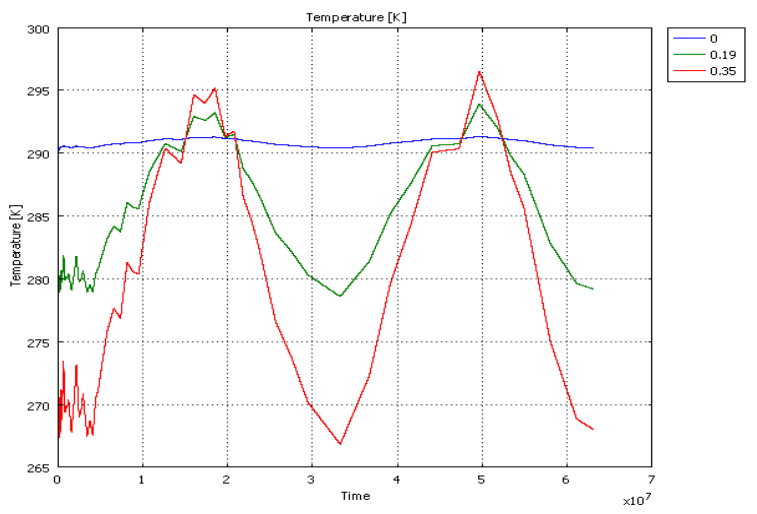

Figure 6. Temperature variation simulating of predicted values

Resistance to heat transfer in several European countries are considered. Resistance to heat transfer of three-layer envelope where internal and exterior layers are precast layers and heat insulation is cellular polystyrene against heat insulation layer depth is examined.

In this study different models of time series which describes air temperature variation in Minsk were considered. Obtained additive model describes original time series with satisfactory precision for practical using and provides air temperature prediction with satisfactory precision for practical application: high coefficient of determination and low standard deviation. Obtained additive time series model allows forecast of heat transfer in capillary-porous structures of building constructions.

Table 4. Parameters of three-layered envelope

\begin{tabular}{llll}
\hline Parameters & Layer 1 & Layer 2 & Layer 3 \\
\hline Material & reinforced concrete & cellular polystyrene & reinforced concrete \\
Depth $\mathrm{d}$ in $\mathrm{m}$ & 0.095 & 0.180 & 0.075 \\
Density $\rho$ in $\mathrm{kg} / \mathrm{m}^{3}$ & 2500 & 25 & 2500 \\
Heat capacity $\mathrm{c}_{\mathrm{p}}$ in $\mathrm{J} /(\mathrm{kg} * \mathrm{~K})$ & 840 & 1340 & 840 \\
Thermal conductivity $\lambda$ in $\mathrm{W} /(\mathrm{m} * \mathrm{~K})$ & 2.04 & 0.052 & 2.04 \\
\hline
\end{tabular}




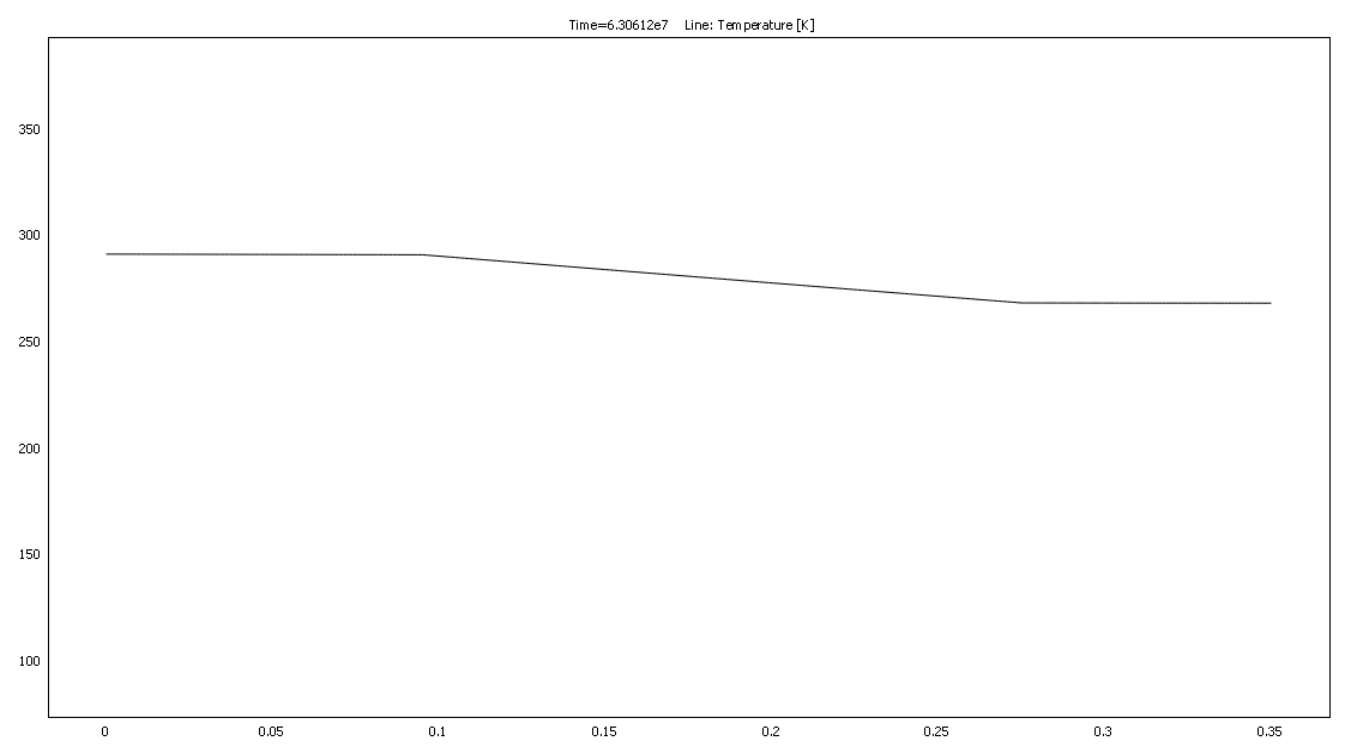

Figure 5. Temperature profile

\section{Acknowledgements}

This study was carried out in the frame of grant of Ministry of Education of Belarus. We also wish to thank Mr. A. Polishjuk, director of State Institution «National Meteorology Centre», for given air temperature data, and Dr. Gishkeluk, for his consultations and advice.

\section{References}

[1] The national energy efficiency program for 2011 - 2015 years.

[2] Crosscutting agenda for design, building and reconstruction of power efficient apartment buildings in Belarus for 2009-2010 years and prospect to 2020 year.

[3] J. A. Clarke. Energy Simulation in Building Design. Adam Hilger Ltd., Bristol and Boston, 1985.

[4] H. Hens, editor (1995) Heat, Air and Moisture Transfer in Insulated Envelope Parts, several volumes. International Energy Agency, IEA, Energy Conservation in Buildings and Community Systems (BCS), Annex 24.
[5] Technical code of Belarus 45-2.04-43-2006(02250). Building heat engineering. Building design standard.

[6] S. P. Kundas, I. A. Gishkeluk, V. I. Kovalenko, O. S. Hilko. Computer modelling of contaminant migration in natural disperse media. Minsk, ISEU Press, 2011.

[7] O. Seppanen. Requirements for building energy efficiency in EU countries, Energy saving, №7/2010.

[8] S. Kundas and E. Kresova. Forecasting of air temperature variation in heat transfer tasks of capillary-porous structures. In Proceedings of the First Virtual International Conference, Advanced Research in Scientific Areas, Slovak Republic, 2012.

[9] M.D. Dettinger, M.Ghil, C.M.Strong, W.Weibel, and P.Yiou, Software expedites singular-spectrum analysis of noisy time series, Eos Trains. AGU, 76(2), 12, 1995.

[10] E.V. Kresova, S.P. Kundas. Time series analysis method application for forecasting of climate factors variations in heat and moisture transfer tasks. In Proceedings of the twelfth International Scientfic Conference, Sakharov Readings: Environmental Problems of the XXI century, Minsk, Belarus, 2012. 